\title{
Heat transfer and thermal stress analysis in grooved tubes
}

\author{
VEYSEL ÖZCEYHAN and NECDET ALTUNTOP \\ Erciyes Üniversitesi Mühendislik Fakültesi, Makine Mühendisliği Bölümü, \\ 38039 Kayseri,Turkey \\ e-mail: ozceyhan@erciyes.edu.tr
}

MS received 28 April 2004; revised 11 February 2005

\begin{abstract}
Heat transfer and thermal stresses, induced by temperature differences in the internally grooved tubes of heat transfer equipment, have been analysed numerically. The analysis has been conducted for four different kinds of internally grooved tubes and three different mean inlet water velocities. Constant temperature was applied from the external surface of the tube. Energy and governing flow equations were solved using finite difference scheme. Finite element method (FEM) was used to compute the thermal stress fields. Grooving effects on the thermal stress ratio have been discussed. As a result, maximum thermal stress occurs in the case of $p=d$ for all water inlet velocities. The maximum thermal stress ratio positions inside the tube have been indicated as MX for all investigated cases. In the light of the thermal stress values, various designs can be applied to reduce thermal stress in grooved tubes.
\end{abstract}

Keywords. Heat transfer; thermal stress; grooved tubes.

\section{Introduction}

Heat transfer in pipe flow has very wide applications area in industry. Heat exchangers are some of the most widely used applications. Heat exchangers are devices that alow heat transfer between two fluids that have different temperatures without physical contact between them. Heat transfer increment is generally crucial for some reasons, such as saving energy and material resources. Therefore, compact heat exchangers that have low-weight and high level of performance, must be designed for the heat-exchanger industry. Enhanced surfaces have been successfully used in the heat transfer industry to obtain more compact and efficient units (Zimparov 2002). Heat transfer enhancement technology has been widely used in heat exchanger in the refrigeration, automotive and process industries among others (Webb 1994; Bergles 1997). The heat transfer enhancement has been analysed by various methods in order to have compact heat exchangers (Kakaç et al 1980). Ligrani et al (1980) have compared heat transfer augmentation techniques. Heat transfer augmentation techniques for several geometries and boundary conditions have been examined in previous works (Adachi \& Uehara 2001; Zimparov 2002; Özceyhan 2002; Wang \& Sundén 2002; Yang \& Hwang 2003). 
Herman \& Kang (2002) state that grooved channels are frequently encountered, including on heat transfer surfaces of heat exchangers, during cooling of electronic equipment and in nuclear reactor cores, as well as in biomedical and aerospace applications.

There has been some work on grooved surfaces in channels or tubes (Ghaddar et al 1986; Brognaux et al 1997; Graham et al 1998; Cavallini et al 1999; Wirtz et al 1999; Goto et al 2001; Park \& Choi 2001; Herman \& Kang 2002; Wang et al 2003; Izumi et al 2004). The heat transfer increase and pressure drop in the helically grooved, horizontal micro-fin tubes were investigated by Wang et al (2003). Many kinds of internally grooved tubes have been investigated to improve the performance of air-conditioning heat exchangers for HFC refrigerants (Cavallini et al 1999; Kedzierski \& Goncalves 1999; Goto et al 2001). Park \& Choi (2001) have shown that grooved or fluted tubes are widely used in modern heat exchangers.

Brognaux et al (1997) expressed heat transfer and friction characteristics for single-phase flow in single-grooved and cross grooved micro-fin tubes. They have found that the microfin tubes have enhanced heat transfer to as high as 1.8 times that of smooth tubes. Threedimensional flow and augmented heat transfer in a symmetrically grooved channel have been analyzed by Greiner et al (2000). They have carried out their analysis for $180 \leq \mathrm{Re} \leq 1600$ with constant temperature boundary condition. Lorenz et al (1995) also investigated the distribution of the local convection-coefficient in a transverse-grooved channel.

The tube is heated externally while the flow passes through it. Thus, a high temperature gradient is introduced across the tube. This high temperature gradient causes thermal stresses that sometimes play an important role in the case of tube failure. Therefore, the thermal stresses must be analysed in grooved tubes. In the tube material, thermal stress calculations are very difficult by using the analytical method due to its complicated configuration and boundary conditions (Lui et al 1999).

The large majority of existing grooved tube investigations focus only on heat or mass transfer. They consider grooving geometry, grooving materials, grooving configuration, channel geometry, and other parameters. Only a few recent studies examine the thermal stress characteristics through passages with grooved surface. There are some researches that have been published related to thermal stresses in the tube (Lui et al 1999; Al-Zaharnah et al 2000, 2001a, 2001b; Özceyhan 2005). The thermal stresses induced by temperature differences in the tube of heat transfer equipment were investigated by Lui et al (1999). The thermal stresses have been analysed in smooth tube for different boundary conditions and different pipe materials (Al-Zaharnah et al 2000, 2001). However, not many research papers have been published yet about the thermal stress in grooved tubes.

The objective of this work is to investigate the conjugate heat transfer and thermal stress distributions in the grooved tube. The flow is assumed to be fully developed and constant temperature is applied through the external surface of the tube. The governing flow, energy and stress equations have been solved numerically. Smooth tubes have also been considered in order to compare then with the grooved tubes. The study also includes the effects of the distances between two grooves to the diameter ratio of the tube. Temperature and thermal stress contours of the grooved tube have been presented for four different distances between two grooves and three-water inlet velocities.

\section{Mathematical modelling}

Figure 1a shows the investigated geometry. In heat transfer, there are two things to be considered, conduction inside the tube and convection from the inner surface of the tube to the fluid. Commercial steel has been selected as tube material. The temperature distribution inside the 


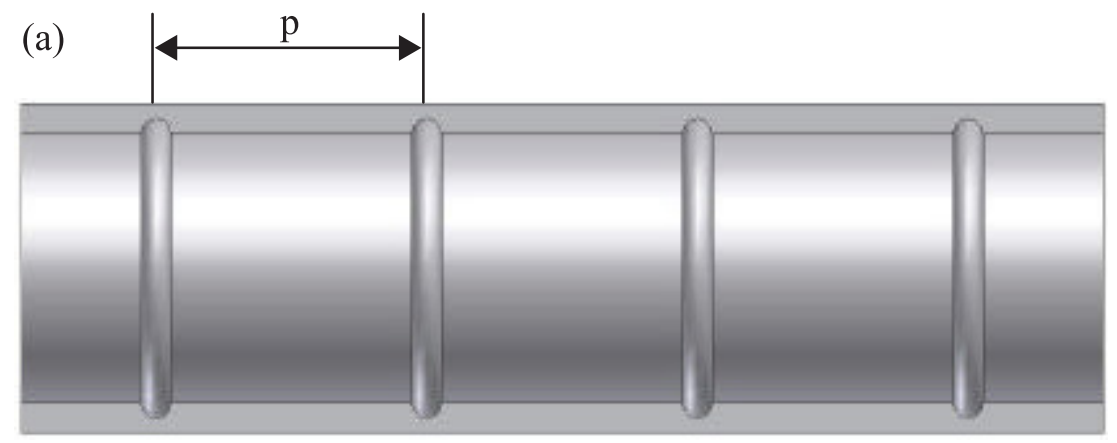

(b)

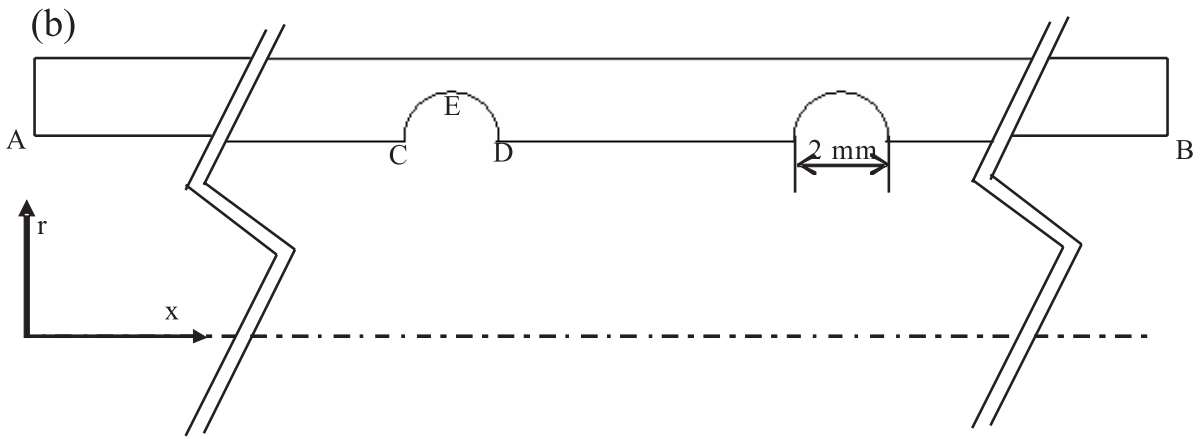

Figure 1. (a) Mechanical model for grooved tube; (b) Physical coordinate system and boundary conditions.

solid tube is solved by a two-dimensional heat conduction equation. The analysis is based on the steady-state, two-dimensional continuity, momentum and energy equations.

The governing flow equations can be written as below.

Continuity equation:

$$
\frac{\partial}{\partial x}\left(\rho v_{x}\right)+\frac{\partial}{\partial r}\left(\rho v_{r}\right)+\frac{\rho v_{r}}{r}=0 .
$$

For 2D geometries, axial and radial momentum conservation equations are given by

$$
\begin{aligned}
\frac{1}{r} \frac{\partial}{\partial x}\left(r \rho v_{x} v_{x}\right)+\frac{1}{r} \frac{\partial}{\partial r}\left(r v_{r} v_{x}\right)= & -\frac{\partial p}{\partial x}+\frac{1}{r} \frac{\partial}{\partial x}\left[r \mu\left(2 \frac{\partial v_{x}}{\partial x}-\frac{2}{3}(\nabla \cdot v)\right]\right. \\
& +\frac{1}{r} \frac{\partial}{\partial r}\left[r \mu\left(\frac{\partial v_{x}}{\partial r}+\frac{\partial v_{r}}{\partial x}\right)\right]+F_{x}
\end{aligned}
$$

and

$$
\begin{aligned}
\frac{1}{r} \frac{\partial}{\partial r}\left(r \rho v_{x} v_{r}\right)+\frac{1}{r} \frac{\partial}{\partial r}\left(r \rho v_{r} v_{r}\right)= & -\frac{\partial p}{\partial r}+\frac{1}{r} \frac{\partial}{\partial x}\left[r \mu\left(\frac{\partial v_{r}}{\partial x}+\frac{\partial v_{x}}{\partial r}\right)\right] \\
& +\frac{1}{r} \frac{\partial}{\partial r}\left[r \mu\left(2 \frac{\partial v_{r}}{\partial r}-\frac{2}{3}(\nabla \cdot \boldsymbol{v})\right)\right] \\
& -2 \mu \frac{v_{r}}{r^{2}}+\frac{2}{3} \frac{\mu}{r}(\nabla \cdot \boldsymbol{v})+\rho \frac{v_{z}^{2}}{r}+F_{r},
\end{aligned}
$$


where

$$
\nabla \cdot \boldsymbol{v}=\frac{\partial v_{x}}{\partial x}+\frac{\partial v_{r}}{\partial r}+\frac{v_{r}}{r},
$$

and $v_{z}$ is the swirl velocity.

Hence, a standard $k-\varepsilon$ turbulance model is used in the simulations. In the derivation of the $k-\varepsilon$ model, the flow is assumed to be fully turbulent and the effects of molecular viscosity are negligible. The turbulence kinetic energy, $k_{t}$, and its rate of dissipation, $\varepsilon$, are obtained from the following transport equations as (FLUENT 2001)

$$
\frac{\partial}{\partial x}\left(\rho k_{t} v_{x}\right)=\frac{\partial}{\partial r}\left[\left(\mu+\frac{\mu_{t}}{\sigma_{k}}\right) \frac{\partial k_{t}}{\partial r}\right]+G_{k}+G_{b}-\rho \varepsilon-Y_{M}
$$

and

$$
\frac{\partial}{\partial x}\left(\rho \varepsilon v_{x}\right)=\frac{\partial}{\partial r}\left[\left(\mu+\frac{\mu_{t}}{\sigma_{\varepsilon}}\right) \frac{\partial \varepsilon}{\partial r}\right]+C_{1 \varepsilon} \frac{\varepsilon}{k_{t}}\left(G_{k}+C_{3 \varepsilon} G_{b}\right)-C_{2 \varepsilon} \rho \frac{\varepsilon^{2}}{k_{t}},
$$

where

$G_{k}$ represents the generation of turbulence kinetic energy due to the mean velocity gradients,

$$
G_{k}=-\rho v_{x}^{\prime} v_{r}^{\prime}\left(\partial v_{r} / \partial x\right) .
$$

$G_{b}$ is the generation of turbulence kinetic energy due to buoyancy

$$
G_{b}=\beta g_{x} \frac{\mu_{t}}{\operatorname{Pr}_{t}} \frac{\partial T}{\partial x},
$$

where $\operatorname{Pr}_{t}$ is the turbulent Prandtl number for energy, $g_{x}$ is the component of the gravitational vector in the $x$ direction, and the coefficient of thermal expansion, $\beta$, is defined as

$$
\beta=-\frac{1}{\rho}\left(\frac{\partial \rho}{\partial T}\right)_{P} .
$$

$Y_{M}$ represents the contribution of the fluctuating dilatation in compressible turbulence to the overall dissipation rate.

The term, $Y_{M}$, is included in (5). This term is modelled according to a proposal by Sarkar \& Balakrishnan (1990).

$$
Y_{M}=2 \rho \varepsilon M_{t}^{2},
$$

where $\mathrm{M}_{t}$ is the turbulent Mach number, defined as

$$
\mathrm{M}_{t}=\left(k_{t} / a^{2}\right)^{1 / 2},
$$

where $a \equiv(\gamma R T)^{1 / 2}$ is the speed of sound.

$C_{1 \varepsilon}, C_{2 \varepsilon}$, and $C_{3 \varepsilon}$ are constants.

$\sigma_{k}$ and $\sigma_{\varepsilon}$ are the turbulent Prandtl numbers for $k_{t}$ and $\varepsilon$, respectively.

The turbulent (or eddy) viscosity, $\mu_{t}$, can be found from the formula as:

$$
\mu_{t}=\rho C_{\mu}\left(k_{t}^{2} / \varepsilon\right),
$$

where $C_{\mu}$ is a constant. 
The model constants $C_{1 \varepsilon}, C_{2 \varepsilon}, C_{\mu}, \sigma_{k}$ and $\sigma_{\varepsilon}$ have the following values (Launder \& Spalding 1972)

$$
C_{1 \varepsilon}=1.44, C_{2 \varepsilon}=1.92, C_{\mu}=0.09, \sigma_{k}=1.0, \sigma_{\varepsilon}=1.3 .
$$

These default values have been determined from experiments with air and water for fundamental turbulent shear flows including homogeneous shear flows and decaying isotropic grid turbulence (FLUENT 2001).

In the solid side, the governing conduction equation is:

$$
\frac{1}{r} \frac{\partial}{\partial r}\left(r \frac{\partial T}{\partial r}\right)+\frac{\partial^{2} T}{\partial x^{2}}=0 .
$$

\subsection{Boundary conditions}

The computational domain is illustrated in figure $1 \mathrm{~b}$. The boundary conditions of the above equations are as below.

(a) Inlet boundary conditions:

$$
v=2 \cdot v_{m} \cdot\left(1-\left(r^{2} / r_{i}^{2}\right)\right), \quad T=T_{\text {inlet }}
$$

and at the tube axis,

$$
\partial v_{x} / \partial r=0 \text { and } \partial T / \partial r=0 .
$$

(b) Tube boundary $(A-B)$ :

No-slip conditions are considered at the tube wall,

$$
\text { At } r= \pm r_{i} \text {, then } v_{x w}=0 \text { and } v_{r w}=0 .
$$

(c) Interfacial boundary $C-E$ and $E-D$ :

$$
\begin{aligned}
v_{x f} & =v_{x w}, \quad v_{r f}=v_{r w}, \quad p_{f}=p_{w}, \\
\frac{\partial v_{x f}}{\partial x} & =\frac{\partial v_{x w}}{\partial x}, \quad \frac{\partial v_{r f}}{\partial x}=\frac{\partial v_{r w}}{\partial x}, \quad \frac{\partial v_{x f}}{\partial r}=\frac{\partial v_{x w}}{\partial r} \text { and } \frac{\partial v_{r f}}{\partial r}=\frac{\partial v_{r w}}{\partial r}, \\
T_{f} & =T_{w}, k_{f} \frac{\partial T_{f}}{\partial x}=k_{e} \frac{\partial T_{w}}{\partial x} \text { and } k_{f} \frac{\partial T_{f}}{\partial r}=k_{e} \frac{\partial T_{w}}{\partial r} .
\end{aligned}
$$

$k_{e}$ is the effective thermal conductivity as given by Fu et al (1996).

(d) At the outer surface:

Constant temperature is assumed at the external surface of the tube:

$$
r= \pm r_{o} \text { and } 0 \leq x \leq L, \rightarrow T_{\text {out }}=450 \mathrm{~K} .
$$

(e) Exit boundary condition:

A zero gradient condition except the velocity component $v$ is employed across the outlet boundary (Yang \& Hwang 2003). 
Governing stress equations (Fauple \& Fisher 1981):

$$
\begin{aligned}
\sigma_{\theta} & =\frac{E \cdot \alpha}{(1-\varsigma) \cdot r^{2}}\left[\frac{r^{2}+r_{i}^{2}}{r_{o}^{2}-r_{i}^{2}} \cdot \int_{r_{i}}^{r_{o}} T(r) \cdot r \cdot \mathrm{d} r+\int_{r_{i}}^{r} T(r) \cdot r \cdot \mathrm{d} r-T(r) \cdot r^{2}\right] \\
\sigma_{r} & =\frac{E \cdot \alpha}{(1-\varsigma) \cdot r^{2}}\left[\frac{r^{2}-r_{i}^{2}}{r_{o}^{2}-r_{i}^{2}} \cdot \int_{r_{i}}^{r_{o}} T(r) \cdot r \cdot \mathrm{d} r-\int_{r_{i}}^{r} T(r) \cdot r \cdot \mathrm{d} r\right] \\
\sigma_{\theta} & =\frac{E \cdot \alpha}{1-\varsigma}\left[\frac{2}{r_{o}^{2}-r_{i}^{2}} \cdot \int_{r_{i}}^{r_{o}} T(r) \cdot r \cdot \mathrm{d} r-T(r)\right] .
\end{aligned}
$$

The effective stress according to Von-Mises theory (Fauple \& Fisher 1981) is,

$$
\sigma_{\text {eff }}=\left(\sigma_{\theta}^{2}+\sigma_{r}^{2}+\sigma_{x}^{2}-\left(\sigma_{\theta} \sigma_{r}+\sigma_{\theta} \sigma_{x}+\sigma_{r} \sigma_{x}\right)\right)^{1 / 2} .
$$

The assumptions used in the present study are as below.

- The flow is steady, turbulent and two-dimensional

- Thermal conductivity of the tube material does not change with temperature

- The tube material is homogeneous and isotropic

Calculations have been performed for four different grooving pitch values and three mean flow velocities as $0.3,0.4$ and $0.5 \mathrm{~m} / \mathrm{s}$.

The physical values in these mathematical expressions are:

$$
\begin{array}{lll}
L=0.072 \mathrm{~m}, & r_{i}=0.009 \mathrm{~m}, & r_{o}=0.011 \mathrm{~m}, \\
T_{\text {out }}=450 \mathrm{~K}, & v_{m}=0.3,0.4 \text { and } 0.5 \mathrm{~m} / \mathrm{s}, & t=2 \mathrm{~mm} \\
p=d / 2, d, 3 d / 2 \text { and } 2 d, & C p_{\text {water }}=4183 \mathrm{~J} / \mathrm{kgK}, & k_{\text {water }}=0.5984 \mathrm{~W} / \mathrm{mK}, \\
v_{\text {water }}=1.00410^{-6} \mathrm{~m}^{2} / \mathrm{s}, & \rho_{\text {water }}=997.13 \mathrm{~kg} / \mathrm{m}^{3} & T_{\text {inlet }}=300 \mathrm{~K}, \\
E_{\text {steel }}=210 \mathrm{GPa}, & \alpha_{\text {steel }}=11.710^{-6} \mathrm{C}^{-1}, & \zeta_{\text {steel }}=0.3 .
\end{array}
$$

\section{Numerical solution}

Numerical calculations have been made for two-dimensional, steady conjugate heat transfer of forced convection, and conduction in grooved tubes with constant outer surface temperature. Two different computer codes have been used to solve the governing equations by the finite difference method for conjugate heat transfer calculation and finite element method for thermal stress analysis.

Eddy diffusivity approximation has been used for temperature field calculations of the turbulent heat flux. A $\operatorname{Pr}_{t}$ value of 0.85 is used in this paper for all calculations as by Ooi et al (2002). The value is between 0.73 and 0.92 in the literature, and 0.85 is generally acceptable (Kays 1994). Second-order upwind-biased discretization has been used for all governing equations. All quantities were solved in a segregated manner at the cell faces as by Ooi et al (2002). The FLUENT (2001) computer code was used to solve equations for the conjugate heat transfer analysis in grooved-tube flows. The SIMPLE (semi-implicit method for pressurelinked equations) algorithm was used for flow computation. The $k-\varepsilon$ model exists in FLUENT 
(2001). Solutions were assumed to converge when the following convergence criterion is satisfied by every dependent variable at every grid point in the computational domain,

$$
\left|\frac{\varphi^{\text {new }}-\varphi^{\text {old }}}{\varphi^{\text {new }}}\right| \leq \phi,
$$

where $(\varphi)$ in general could be any dependent variable. In this study, $\phi=10^{-5}$ for continuity, momentum, turbulent kinetic energy and turbulent dissipation rate equations. This value is $10^{-6}$ for energy equations. ANSYS (1997) computer code has been used to analyse the thermal stresses with the interior temperatures as boundary conditions for all node. The temperatures of all nodes in the tube have been calculated by FLUENT (2001) computer code. Heat transfers have been analysed within the grooved tube through which the fluid flows, and conduction heat transfers have also been analysed in the solid tubes. In the first step, the temperature distributions of both solid tube and fluid have been calculated. In the second step, the thermal stress analyses have been conducted using the ANSYS computer code and taking the temperatures of all nodes in the solid as boundary conditions arising from the first step.

The thermally developing tube length is considered before the geometry in figure 1 as by Incropera \& DeWitt (1990). The flow is assumed to be thermally developed at the inlet of the grooved tube tube, water enters the tube at $300 \mathrm{~K}$ in all cases.

\subsection{Validation}

The numerical method is used succesfully to solve the governing equations (Özceyhan 2003) to obtain temperature and thermal stress distributions for a wire coil inserted tube. The method gives very good results for both smooth and wire coil inserted tubes. In the present paper, temperature and thermal stress values cannot be compared to those in previous studies because they have calculated thermal stresses and temperature distributions for constant heat flux boundary conditions (Al-Zaharnah et al 2000, 2001; Özceyhan 2005). This is the first study about calculation of thermal stress is in grooved tubes for constant surface temperature boundary conditions. Therefore, results obtained from the numerical method can be assumed to be valid.

\section{Discussion}

The temperature contours of the smooth and grooved tubes are illustrated in figures $2-6$. The temperature distributions in the radial direction along the tube length are nearly constant as in figure 2. Temperature distributions of the grooved tubes are not the same as those of the smooth tubes, as seen in figures 3-6. The inner surface temperatures of smooth tubes are higher than those of grooved tubes because of the heat transfer increment due to the destruction of the laminar sublayers. Hence, heat transfers increase and inner surface temperatures decrease owing to the use of grooved surfaces. Temperature increases at some points on the inner wall of the grooved tube. These points are at almost the midpoint of two grooved points. This increase would supply temperature and also cause thermal stress distribution differences between smooth and grooved tubes. Minimum inner temperature surface has occurred in $p=d / 2$ cases for $0.5 \mathrm{~m} / \mathrm{s}$ mean water velocity, as in figure 3 .

The maximum thermal stresses and positions inside the tubes are important for designing new kinds of heat transfer devices. Figures 7a-10a represent the thermal stresses for all investigated cases. Maximum thermal stress point details are shown in figures $7 \mathrm{~b}-10 \mathrm{~b}$. The 


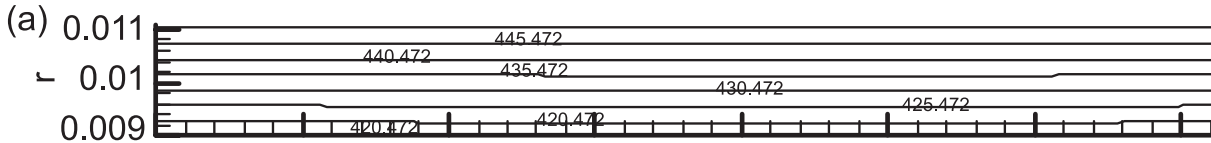

(b) 0.011

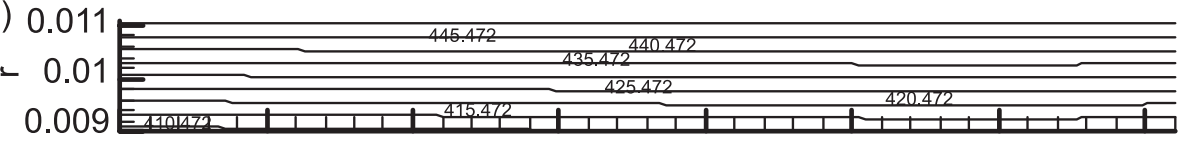

(c) 0.01

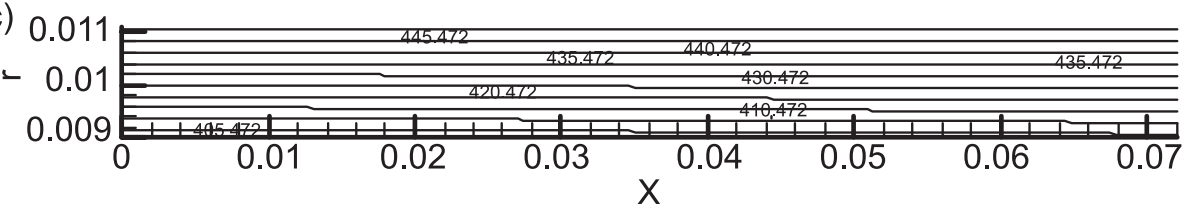

Figure 2. Temperature contours of the smooth tube for $v_{m}=0.3(\mathbf{a}), 0.4(\mathbf{b}), 0.5 \mathrm{~m} / \mathrm{s}(\mathbf{c})$.

(a) 0.011

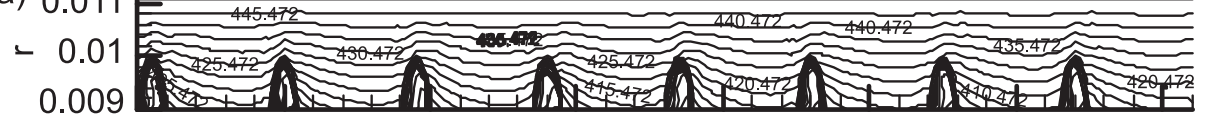

(b) 0.011

$-0.01$ 0.0090201012

(c) 0.011

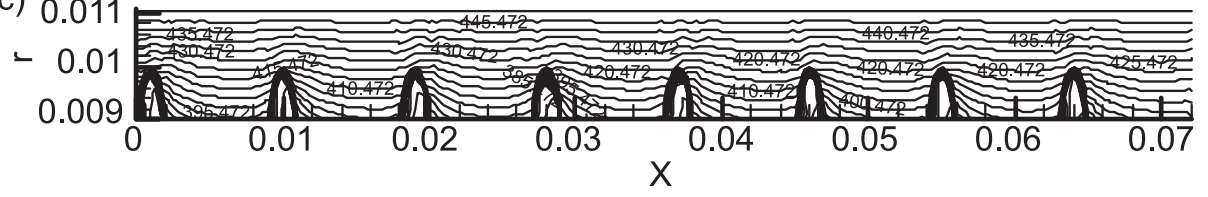

Figure 3. Temperature contours of the tube for $p=d / 2 . v_{m}=0.3(\mathbf{a}), 0.4(\mathbf{b}), 0.5 \mathrm{~m} / \mathrm{s}(\mathbf{c})$.

(a) 0.011

$-0.01$

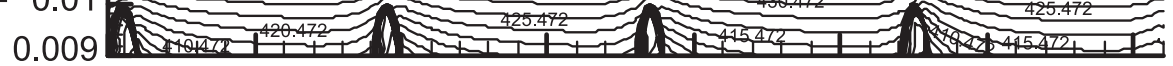

(b) 0.011

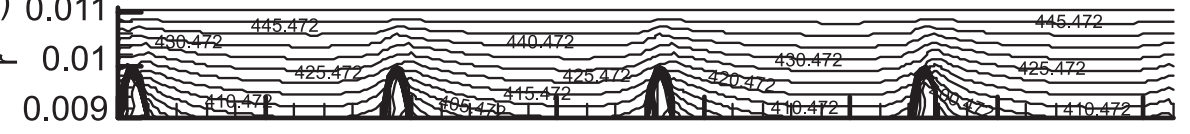

(c) 0.0

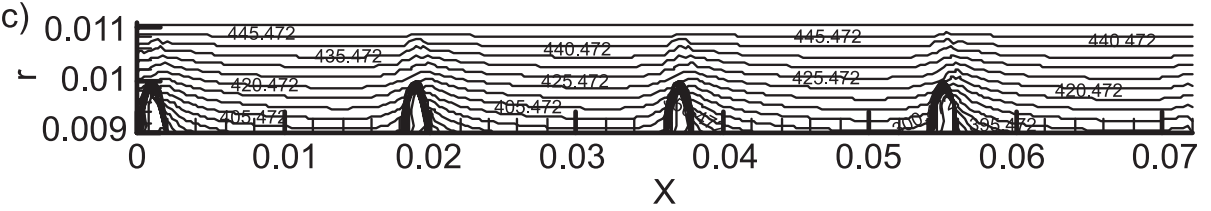

Figure 4. Temperature contours of the tube for $p=d . v_{m}=0.3(\mathbf{a}), 0.4(\mathbf{b}), 0.5 \mathrm{~m} / \mathrm{s}(\mathbf{c})$. 

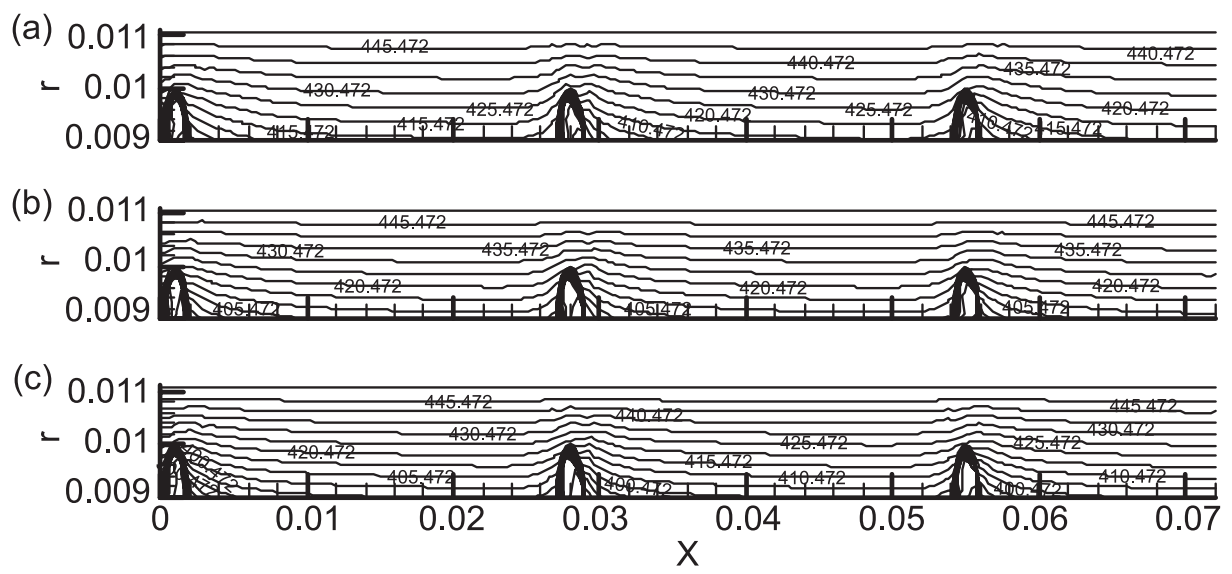

Figure 5. Temperature contours of the tube for $p=3 d / 2 . v_{m}=0 \cdot 3(\mathbf{a}), 0.4(\mathbf{b}), 0.5 \mathrm{~m} / \mathrm{s}(\mathbf{c})$.

minimum and maximum thermal stress points in the tube for all cases have also been indicated as MN and MX respectively. Values and coordinates of MX and MN are given in table 1. Thermal stress distributions of smooth tubes have nearly the same characteristics as their temperature distributions (figure 2) for all mean inlet water velocities. Therefore, thermal stress contours of the smooth tubes are not given here, though the results have been discussed. The thermal stresses of the grooved tubes have contours different from those of smooth tubes as in figures 7-10. Thermal stresses are the maximum at some points near the groove for all investigated cases because of the higher temperature gradients. This result shows us that such points required some surface modifications or treatment in heat exchangers which have grooved surfaces. The maximum thermal stresses of the all grooved tubes are nearly twice as high as those of smooth tubes for the same water inlet velocity. This increment in thermal stress is an important criterion for consideration in the design of new compact heat exchangeres using grooved surfaces to enhance heat transfer.
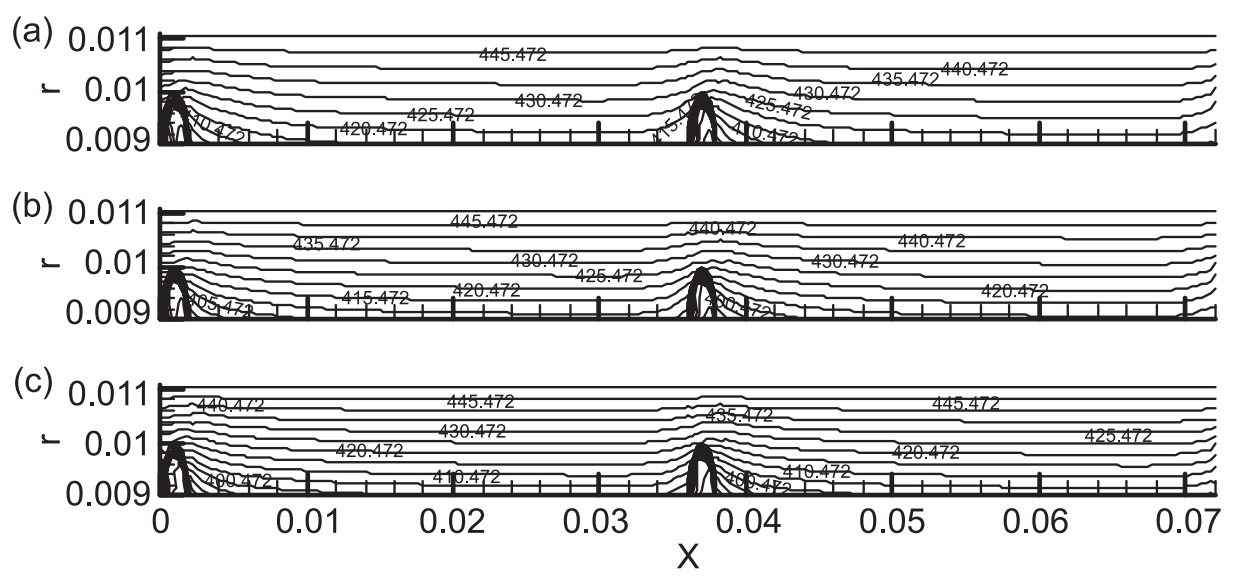

Figure 6. Temperature contours of the tube for $p=2 d . v_{m}=0.3(\mathbf{a}), 0.4(\mathbf{b}), 0.5 \mathrm{~m} / \mathrm{s}(\mathbf{c})$. 


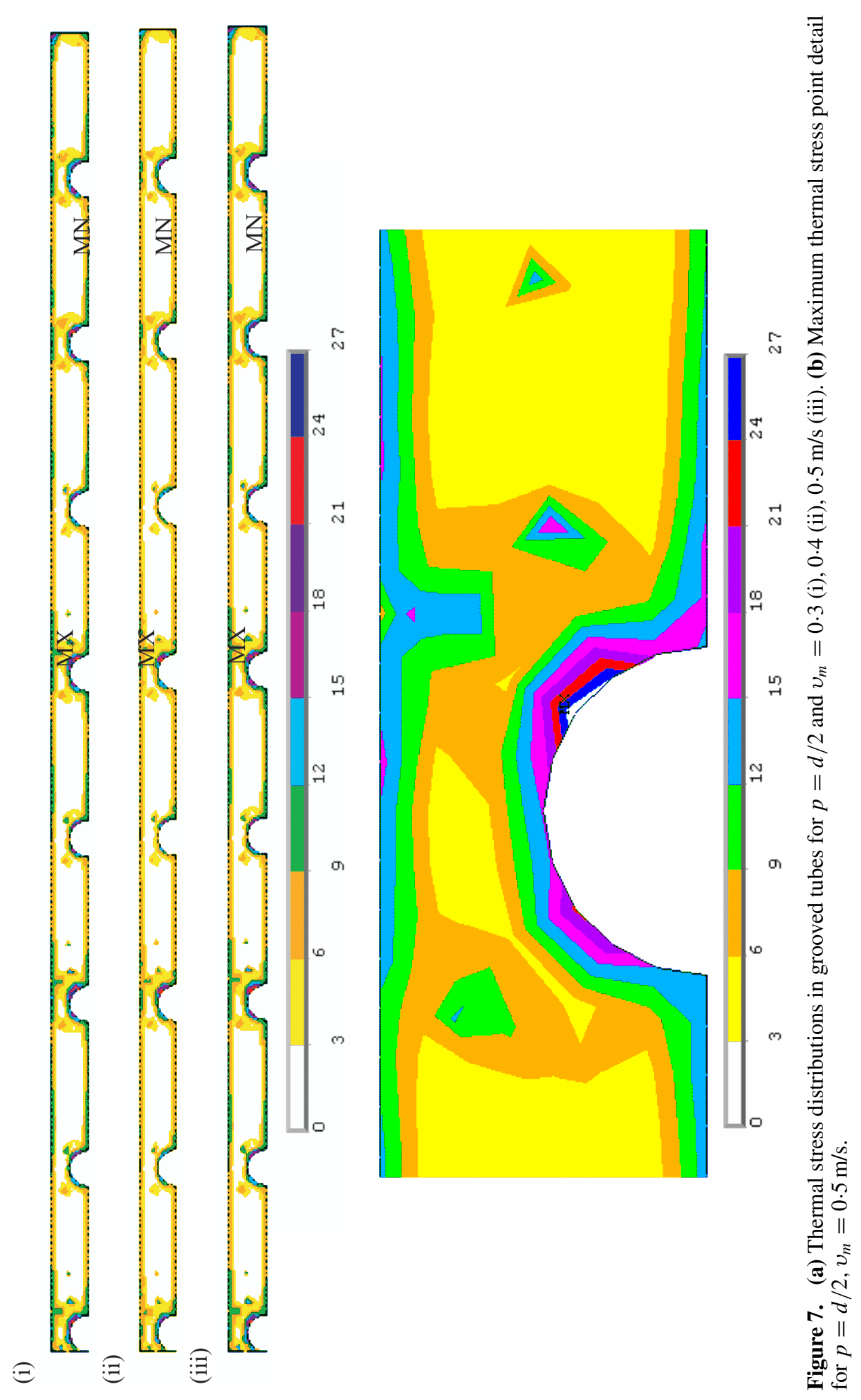




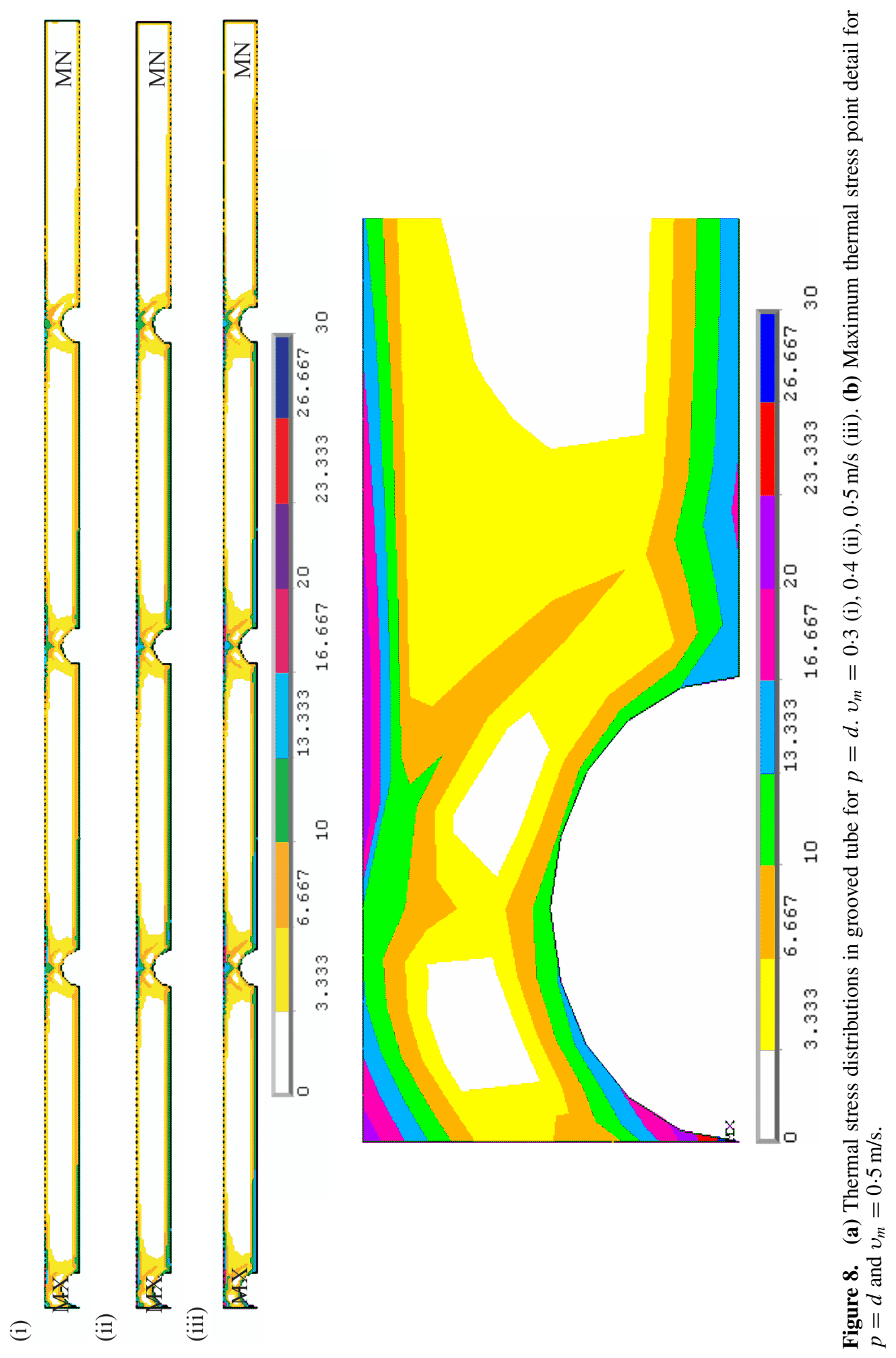




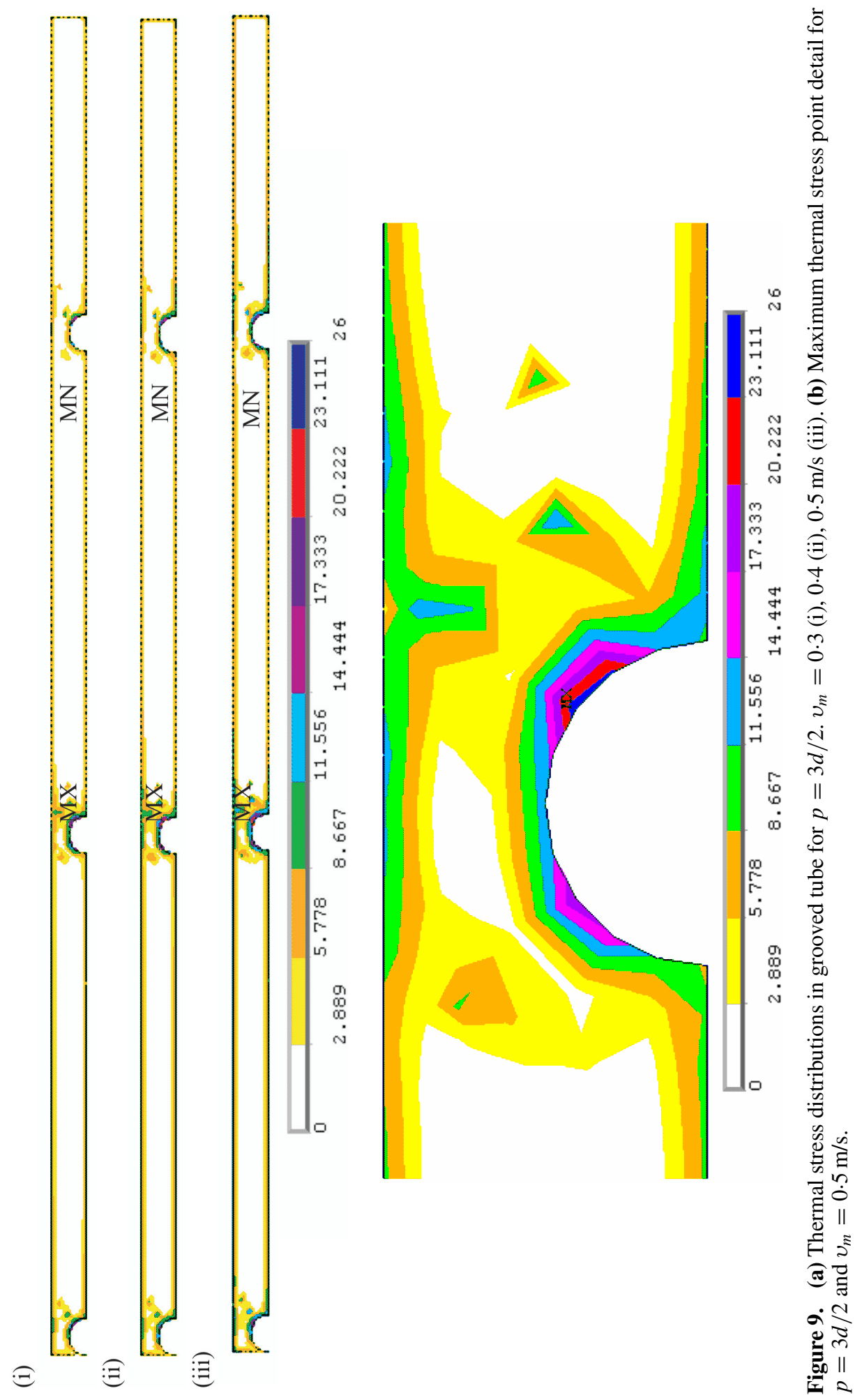




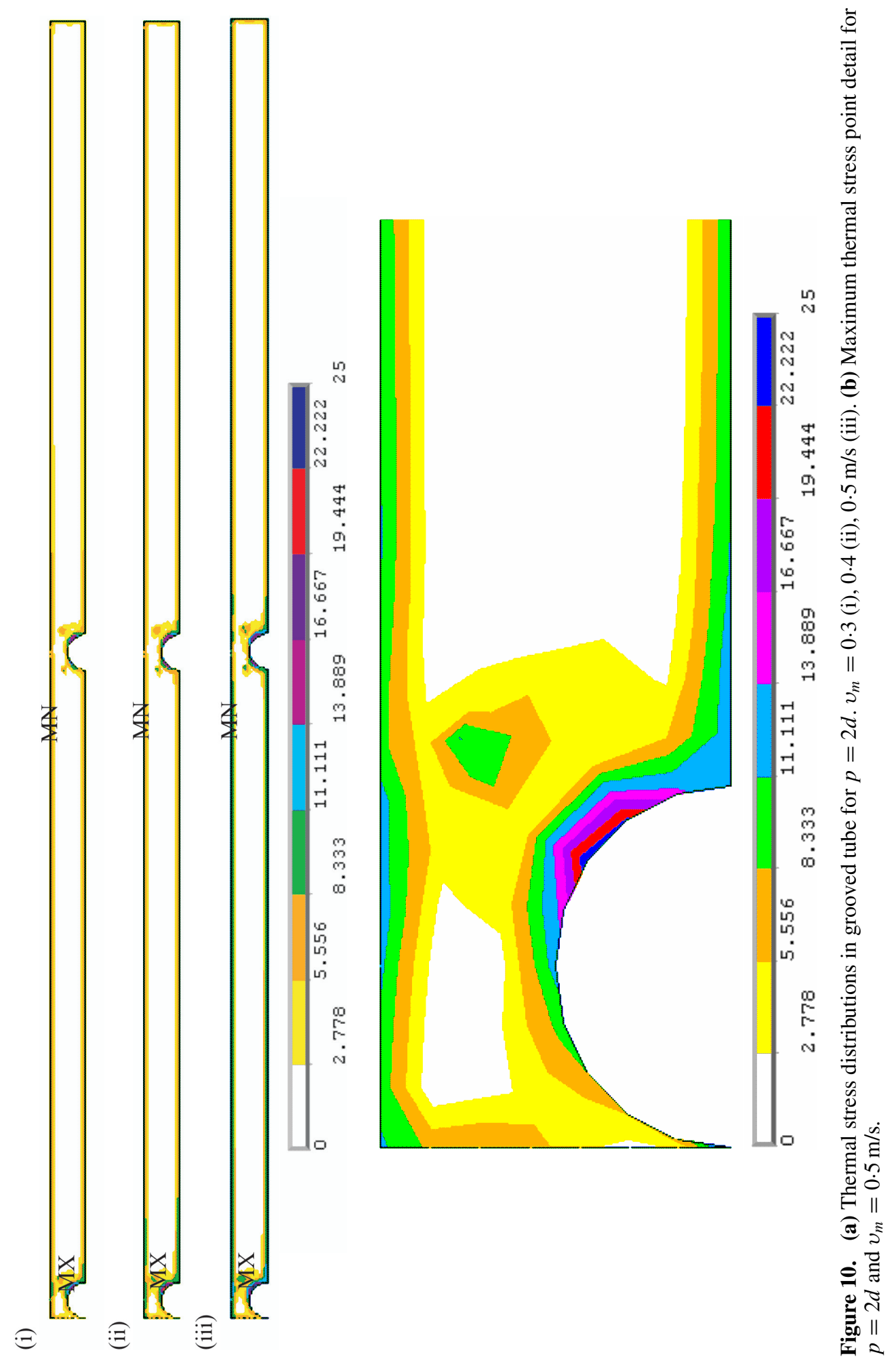


Table 1. Maximum and minimum thermal stresses and their coordinates.

\begin{tabular}{|c|c|c|c|c|c|c|c|}
\hline \multirow[b]{2}{*}{$p=$} & \multirow[b]{2}{*}{$\begin{array}{l}\text { Velocity } \\
(\mathrm{m} / \mathrm{s})\end{array}$} & \multicolumn{3}{|c|}{ Maximum thermal stress } & \multicolumn{3}{|c|}{ Minimum thermal stress } \\
\hline & & $\begin{array}{l}\text { Value } \\
(\mathrm{MPa})\end{array}$ & $\begin{array}{c}X \\
\substack{\text { coordinate } \\
(\mathrm{mm})}\end{array}$ & $\begin{array}{c}r \\
\text { coordinate } \\
(\mathrm{mm})\end{array}$ & $\begin{array}{l}\text { Value } \\
(\mathrm{MPa})\end{array}$ & $\begin{array}{c}X \\
\text { coordinate } \\
(\mathrm{mm})\end{array}$ & $\begin{array}{c}r \\
\text { coordinate } \\
(\mathrm{mm})\end{array}$ \\
\hline & 3 & $22 \cdot 71$ & $37 \cdot 5877$ & $9 \cdot 809$ & $1.2365 \times 10^{-2}$ & 68.9564 & $10 \cdot 3284$ \\
\hline \multirow[t]{3}{*}{$d / 2$} & 4 & $25 \cdot 174$ & $37 \cdot 5877$ & $9 \cdot 809$ & $9.1988 \times 10^{-3}$ & 68.9564 & $10 \cdot 3284$ \\
\hline & 5 & $26 \cdot 81$ & $37 \cdot 5877$ & 9.809 & 1.0848 & $68 \cdot 9564$ & $10 \cdot 3284$ \\
\hline & 3 & $21 \cdot 23$ & $0 \cdot 0$ & $9 \cdot 0$ & $7.0818 \times 10^{-3}$ & $70 \cdot 72$ & $9 \cdot 857$ \\
\hline \multirow[t]{3}{*}{$d$} & 4 & $25 \cdot 856$ & $0 \cdot 0$ & $9 \cdot 0$ & $9.488 \times 10^{-3}$ & 71.018 & 9.857 \\
\hline & 5 & $30 \cdot 056$ & $0 \cdot 0$ & $9 \cdot 0$ & $1.258 \times 10^{-2}$ & $70 \cdot 316$ & 9.857 \\
\hline & 3 & $20 \cdot 886$ & 28.587 & 9.809 & $1.827 \times 10^{-3}$ & 47.479 & 9.854 \\
\hline \multirow[t]{3}{*}{$3 d / 2$} & 4 & 22.656 & 28.587 & 9.809 & $2.227 \times 10^{-3}$ & $48 \cdot 358$ & $910 \cdot 33$ \\
\hline & 5 & $25 \cdot 617$ & 28.587 & 9.809 & $4.64 \times 10^{-3}$ & 47.757 & $10 \cdot 33$ \\
\hline & 3 & 19.433 & 1.5877 & 9.809 & $4.165 \times 10^{-3}$ & 28.558 & $10 \cdot 3305$ \\
\hline \multirow[t]{3}{*}{$2 d$} & 4 & 21.915 & 1.5877 & 9.809 & $4.643 \times 10^{-3}$ & $27 \cdot 357$ & $10 \cdot 3305$ \\
\hline & 5 & $25 \cdot 007$ & 1.5877 & 9.809 & $5.289 \times 10^{-3}$ & $27 \cdot 657$ & $10 \cdot 3305$ \\
\hline & 3 & $11 \cdot 571$ & 35.699 & $9 \cdot 0$ & $1.083 \times 10^{-4}$ & $51 \cdot 31$ & $10 \cdot 42$ \\
\hline \multirow[t]{2}{*}{ Smooth } & 4 & 13.856 & 35.699 & $9 \cdot 0$ & $5.771 \times 10^{-4}$ & 31.48 & $9 \cdot 0$ \\
\hline & 5 & $16 \cdot 087$ & 38.794 & $11 \cdot 0$ & $1.371 \times 10^{-3}$ & $33 \cdot 40$ & $11 \cdot 0$ \\
\hline
\end{tabular}

Maximum thermal stress variation with mean inlet velocity for grooved tubes with different pitches is shown in figure 11. The maximum thermal stress is seen in the $p=d$ cases, where the mean water velocity is $5 \mathrm{~m} / \mathrm{s}$. Thermal stress ratios have lower values in the case of $p=2 d$ in all investigated cases.

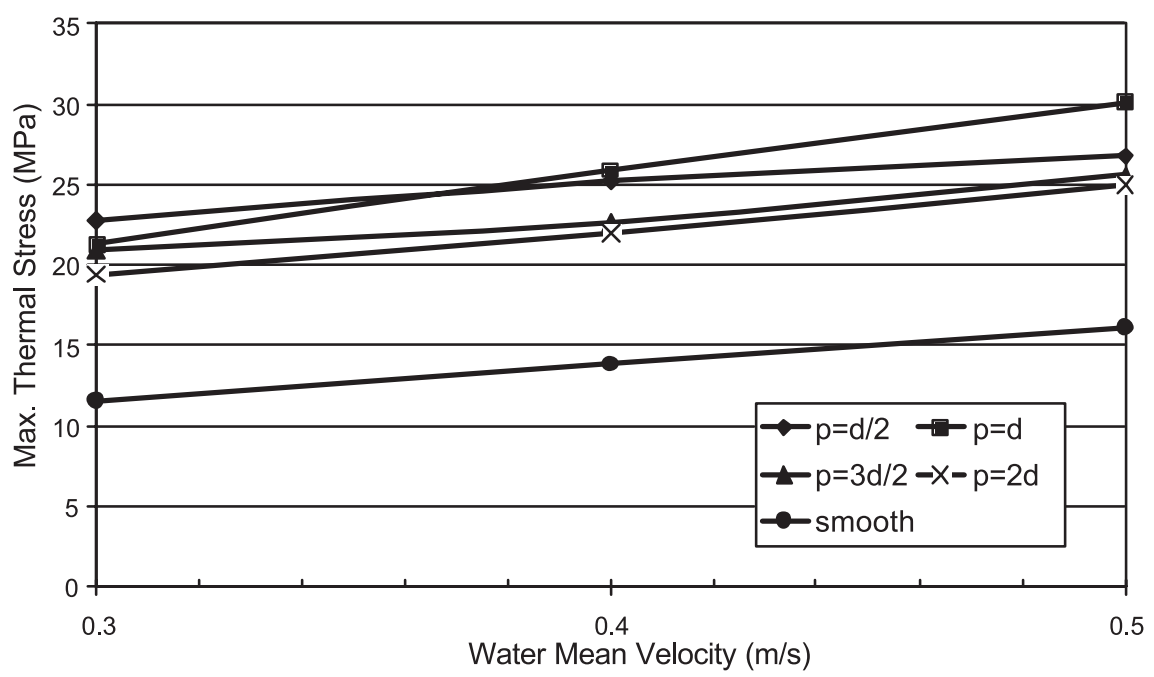

Figure 11. Maximum thermal stress variations according to the groove distance and water inlet velocity. 


\section{Conclusion}

Radial and axial heat conduction in smooth and grooved tubes with constant surface temperature is considered in the present study. Temperature and thermal stress distributions inside the tubes for three different velocities and four different grooving distances have been presented. Thermal stresses in smooth tubes have also been analysed for comparison tubes with grooved surfaces.

In grooved tubes, the maximum thermal stresses increase to values nearly twice that of smooth tubes for all water inlet velocities. This increment in thermal stress is an important criterion in the design of new compact heat exchangers using grooved surfaces to enhance heat transfer.

In general, the maximum thermal stresses (MX) occur near the grooved parts of the tubes for all water inlet velocities because of the higher temperature gradient; thermal stress increases when the volume flow rate of the fluid increases. Maximum thermal stress ratios has occur in $p=d$ cases for $0.5 \mathrm{~m} / \mathrm{s}$ mean water inlet velocity.

Consequently, location of the maximum and minimum stress ratios inside the tube depends on the distance between two grooves, and the volume flow rate of the fluid. The types of grooves and the distance between them must be considered to avoid thermal stress effects inside the tube, and/or surface modifications must be applied to surfaces where the maximum thermal stresses occur.

This study provides ideas on the design of new heat exchangers using grooved surfaces for heat transfer augmentation.

The authors would like to thank the Erciyes University Research Fund for financial support (through a project grant).

\section{List of symbols}

$C_{p} \quad$ specific heat of fluid $(\mathrm{J} / \mathrm{kgK})$;

$E$ modulus of elasticity of the tube material (GPa);

$g_{x} \quad$ component of the gravitational vector in the $x$ direction $\left(\mathrm{m} / \mathrm{s}^{2}\right)$;

$G_{k}$ generation of turbulence kinetic energy due to the mean velocity gradients $\left(\mathrm{kg} / \mathrm{m} . \mathrm{s}^{3}\right)$;

$G_{b} \quad$ generation of turbulence kinetic energy due to buoyancy $\left(\mathrm{kg} / \mathrm{m} . \mathrm{s}^{6}\right)$;

$k_{f}$ thermal conductivity of the fluid (W/m.K);

$k_{t} \quad$ turbulence kinetic energy $\left(\mathrm{m}^{2} / \mathrm{s}^{2}\right)$;

$k_{e} \quad$ effective thermal conductivity (W/m.K);

$k_{w} \quad$ thermal conductivity of the solid (W/m.K);

$L \quad$ length of the tube (m);

$M_{t} \quad$ turbulent Mach number;

$P \quad$ pressure $(\mathrm{Pa})$;

Pr Prandtl number;

$\mathrm{Pr}_{t} \quad$ turbulent Prandtl number for energy;

$R \quad$ universal gas constant $(\mathrm{kJ} / \mathrm{kg}-\mathrm{K})$;

$r$ radial coordinate;

$r_{i} \quad$ tube inner radius (m);

$r_{o} \quad$ tube outer radius $(\mathrm{m})$;

$t \quad$ thickness of the tube (m); 


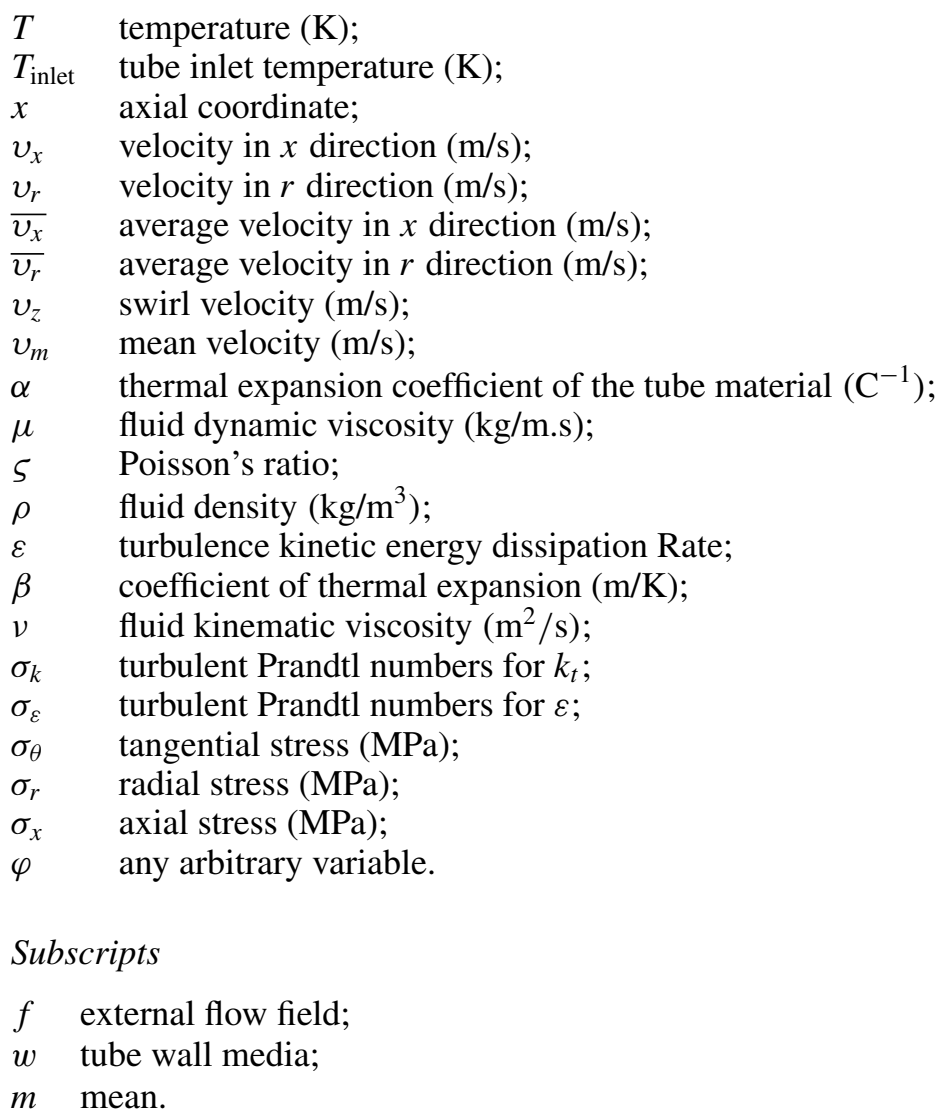

\section{References}

Adachi T, Uehara H 2001 Correlation between heat transfer and pressure drop in channels with periodically grooved parts. Int. J. Heat Mass Transfer 44: 4333-4343

ANSYS 1997 ANSYS 5.3 - The general purpose finite element software, Swanson Analysis Systems, Inc., Houston, TX

Al-Zaharnah I T, Yilbas B S, Hashmi M S J 2000 Conjugate heat transfer in fully developed laminar pipe flow and thermally induced stresses. Comput. Methods Appl. Mech. Engrg. 190: 1091-1104

Al-Zaharnah I, Yilbas B S, Hashmi M S J 2001a Pulsating flow in circular pipes - The analysis of thermal stresses. Int. J. Press. Vessels Piping 78: 567-579

Alzaharnah I T, Hashmi M S, Yilbas B 2001b Thermal stresses in thick-walled pipes subjected to fully developed laminar flow. J. Mater. Process. Technol. 118: 50-57

Bergles A E 1997 Heat transfer enhancement - The encouragement and accomidation of high heat fluxes. J. Heat Transfer, Trans. ASME 119: 8-19

Brognaux L J, Webb R L, Chamra L M, Chung B Y 1997 Single-phase heat transfer in micro-fin tubes. Int. J. Heat Mass Transfer 40: 4345-4357

Cavallini A, Del C, Doretti L, Longo G A, Rossetto L A 1999 New computational procedure for heat transfer and pressure drop during refrigerant condensation inside enhanced tubes. Enhanced Heat Transfer 6: 441-456

Fauple J H, Fisher F E 1981 Engineering design - A synthesis of stress analysis and material engineering (New York: Wiley) 
Fu W S, Huang H C, Liou W Y 1996 Thermal enhancement in laminar channel flow with a porous block. Int. J. Heat Mass Transfer 39: 2165-2175

FLUENT 2001 FLUENT 6·1.22 user's guide. Fluent Incorporated. Centerra Resource Park, 10 Cavendish Court, Lebanon, NH 03766, USA

Graham D, Chato J C, Newell T A 1998 Heat transfer and pressure drop during condensation of refrigerant 134a in an axially grooved tube. Int. J. Heat Mass Transfer 42: 1935-1944

Greiner M, Faulkner R J, Van V T, Tufo H M, Fischer P F 2000 Simulations of three-dimensional flow and augmented heat transfer in a symmetrically grooved channel. Trans. ASME 122: 653-660

Goto M, Inoue N, Ishiwatari N 200 Condensation and evaporation heat transfer of R410A inside internally grooved horizontal tubes. Int. J. Refrigeration 24: 628-638

Ghaddar N K, Korczak B B, Patera A Y 1986 Numerical investigation of inceompressible flow in grooved channels. Part 1. Stability and self-sustained oscillations. J. Fluid Mech. 163: 99-127

Herman C, Kang E 2002 Heat transfer enhancement in a grooved channel with curved vanes. Int. J. Heat Mass Transfer 45: 3741-3757

Izumi M, Kumagai S, Shimada R, Yamakawa N 2004 Heat transfer enhancement of dropwise condensation on a vertical surface with round shaped grooves. Exp. Thermal Fluid Sci. 28: 243-248

Incropera F P, DeWitt D P 1990 Fundamentals of heat and mass transfer 3rd edn (New York: John Wiley \& Sons)

Kakaç S, Shah R K, Aung W 1980 Handbook of single phase convective heat transfer (New York: Wiley) $17 \cdot 1-17.62$

Kays W M 1994 Turbulent Prandtl number - where are we? J. Heat Transfer 116: 284-295

Kedzierski M A, Goncalves J M 1999 Horizontal convective condensation of alternative refrigerants within a micro-fin tube. Enhanced Heat Transfer 6: 161-178

Launder B E, Spalding D B 1972 Lectures in mathematical models of turbulence (London: Academic Press)

Lorenz S, Mukomilow D, Leiner W 1995 Distribution of the heat-transfer coeffcient in a channel with periodic transverse grooves. Exp. Thermal Fluid Sci. 11: 234-242

Lui M S, Dong Q W, Wang D-B, Ling X 1999 Numerical simulation of thermal stress in tube-sheet of heat transfer equipment. Int. J. Press. Vessels Piping 76: 671-675

Ligrani P M, Oliveira M M, Blaskovich T 2003 Comparison of heat transfer augmentation techniques. AIAA J. 41: 337-362

Özceyhan V 2005 Conjugate heat transfer and thermal stress analysis of wire coil inserted tubes that are heated externally with uniform heat flux. Energy Convers. Manage. 46: 1543-1559

Özceyhan V 2002 Experimental investigation of flow and heat transfer in a rib inserted pipe. Ph D thesis, Erciyes University Engineering Faculty, Turkey

Ooi A, Iaccarino G, Durbin P A, Behnia M 2002 Reynolds averaged simulation of flow and heat transfer in ribbed ducts. Int. J. Heat Fluid Flow 23: 750-757

Park I S, Choi D H 2001 Heat and mass-transfer analysis of the condensing film flow along a vertical grooved tube. Int. J. Heat Mass Transfer 44: 4277-4285

Sarkar S, Balakrishnan L 1990 Application of a Reynolds-stress turbulence model to the compressible shear layer. ICASE Report 90-18. NASA CR 182002

Wang L, Sundén B 2002 Performance comparison of some tube inserts. Int. Commun. Heat Mass Transfer 29(1): 45-56

Webb R L 1994 Principles of enhanced heat transfer (New York: John Wiley \& Sons)

Wang H S, Rose J W, Hondab H 2003 Condensation of refrigerants in horizontal microfin tubes: comparison of correlations for frictional pressure drop. Int. J. Refrigeration 26: 461-472

Wirtz R A, Huang F, Greiner M 1999 Correlation of fully developed heat transfer and pressure drop in a symmetrically grooved channel. ASME J. Heat Transfer 121: 236-239

Yang Y T, Hwang C Z 2003 Calculation of turbulent flow and heat transfer in a porous-based channel. Int. J. Heat Mass Transfer 46: 771-780

Zimparov V 2002 Energy conservation through heat transfer enhancement techniques. Int. J. Energy Res. 26: 675-696 